\title{
Probabilidad de la democracia en El Salvador
}

\begin{abstract}
Arturo Urrutia
El Gran Método es una doctrina práctica sobre las alianzas y la disolución de las alianzas, sobre el aprovechamiento de los cambios y el cambio de sus realizaciones, sobre la disociación y el surgimiento de unidades, sobre la interdependencia de los contrarios y la compatibilidad de los contrarios que se excluyen. El Gran Método permite discenir procesos en las cosas y aprovecharlos. Enseña a formular preguntas que hacen posible la acción.
\end{abstract}

Bertolt Brecht. ME-TI: LIBRO DE LOS CAMBIOS

El acuerdo negociado a la guerra salvadorena, desde todo punlo de vista, representa un acontecimiento inusual en la resolución de conflictos de la historia moderna centroamericana. Aunque el proceso iniciado en Sapoá (1988) por el gobierno sandinisla y la "conlra" nicaragüense marca también un hito en esle ámbito de la acción política, el hecho de que el Frente Sandinista de Liberación Nacional (FSLN) perdiera las elecciones generales en 1990, desdibujó las líneas guias que llevaron al desenlace de la negociación en Nicaragua. El peso específico del FSLN en la vida nacional nicaragüense no se adelgazó en esencia como produclo del descalabro electoral, pero si se vio reorientada la dirección de los resultados tinales de la negociación. Lo que pudo haber sido un desarme sin legitimación política para la "contra", al cambiar la cúpula del aparato 
estatal la inserción política de las fuerzas de la contrarrevolución se hizo expedila, al punto que la exigencia de una cuota de poder, no fue una reivindicación marginal'.

Por las caracterlsticas de la confrontación político-militar en El Salvador, lo esperado (de un acuerdo negociado) por parte de las fuerzas populares encabezadas por el FMLN, era una recomposición del poder político a nivel de la estructura del Estado. Inclusive, la perpectiva de las transformaciones socio-económicas históricamente pendientes en el pais, también formaba parte de la agenda a negociar. Sin embargo, lo que "salio" de la lase final del proceso negociador, lampoco se encontraba con exactitud en el cuadro analitico de las luerzas involucradas ${ }^{2}$.

- De manera sintética, pudiera decirse que el período de democracla polittlce que se abre a partir de 1992, solo adquirirá profundidad y apoyo popular masivo, sl la desmilitarización es efectiva. Por el lado del FMLN, es obvio que si se cumplen los acuerdos de paz, en octubre 92 dejará de manera irreversible de comlar con la dimensión militar $\infty$ mo instrumento para la lucha social.

En cambio, la parte de la desmilitarización que le corresponde al actual gobierno activar, no va a tener una dinámica ajena a las dificullades. La Fuerza Armada, siendo el sujelo principal de la militarización historlca que ha vivido el país en este siglo, a no dudar, se verá envuelta en no pocas contradicciones para lograr concretar el objelivo sefnalado por la negociación. A nadie escapa, el hecho de que en el seno de la inslitución castrense (y por extensión en el slstema militar que se prohijo con los sucesivos regimenes politicos), se han incubado los agentes más beligerantes y abanderados de la eliminación física del "enemigo", como el recurso por excelencia para dirimir los conflictos sociales. Y esta actltud politice, no queda eliminada de forma automática por los acuerdos de paz; con éstos se cuestiona de manera contundente el supra-poder que lo miltar ha tenido en el desenvolvimiento socio-político nacional.

La reducción numérica de la Fuerza Armada (que va desde el achicamiento político y militar del ejército, pasando por la eliminación de las fuerzas para-mililares y culminando con la disolución de los cuerpos de seguridad) tiene complicaciones no sólo por que se pierden "redes" significalivas que permitieron la reproducción de los propositos políticos de la institución militar, sino también porque siendo las estructuras militares instancias donde se malerializan las funciones de poder, existen cotos e intereses muy específicos que los acuerdos de paz ponen en entredicho y que en la práctica, de manera inmediata, pueden considerarse como alectados. Nunca ha sido un secreto (aunque sl eslaba vedado por la coacción social, expresarlo) que denlro de la Fuerza Armada -a 
todo nivel- se han gestado muchas de las prácticas de corrupción ahora extendidas a todo el cuerpo social; bastaría rasirear las fuentes primarias del contrabando "comercial", el narcotrálico, mercado negro de armas, etc.

Además habría que apuntar, el status "especial" de que gozó la Fuerza Armada, que casi se convirtió en un agregado socio-político que operaba al margen de la sociedad (legal, pero llegitima por su actuación), que sin llegar como en Guatemala, a conslituirse en segmento de clase social dominante, alimenló los ritmos vitales de la sociedad política y los impuso a la sociedad civil. Y corregir esta "anormalidad" es, entendemos, el espiritu de los acuerdos de paz ${ }^{3}$.

Si vemos retrospectivamente la siluación salvadorena, era más logico que la Democracia Cristiana pudiera "entregar" a la Fuerza Armada, que el partido ARENA. Pero, esla percepción obvia el hecho de que la declsión política de negociar la guerra salvadorefia, está en relación directa (además del carácter sobredelerminante del entorno internacional) con los contenidos y expeclativas del proyecto polílico de modernización politica-económica que distintos grupos empresarlales han venido apuntalando en los úllimos af́os. La Democracia Cristiana no representaba a ningún segmento significativo del capital, en cambio la gestión gubemamental que accedió al poder político del Estado en 1989, encabezada por Alfredo Cristiani Burkard, no es un simple apéndice del partido ARENA, sino que, a nuestro modo de ver, constituye la expresión de un ampllo consenso empresarlal nunca anles alcanzado en el campo dominante, por lo menos en la era "republicana" 4.

$Y$ esto, nos parece básico comprenderlo, porque es uno de los componentes internos que tavorecieron el acuerdo de paz. Al conjunto de la empresa privada, en el marco del nuevo orden mundial, donde una vez más El Salvador queda casi sin opciones (en lo económico fundamentalmente), ya no le interesa seguir atizando los conflictos sociales y menos seguir conviviendo con una guerra que no la paralizó pero si bloqueó sus "impelus productivos". Por ejemplo, la reconversión industrial -que es uno de los escalones a completar, para ponerse al nivel del nuevo ordenamiento económico mundial-, no puede realizarse en medio de agiladas convulsiones sociales. Tampoco la constilución de una plalalorma productiva que haga viable las exportaciones no-Iradicionales para mercados mundiales, de ninguna manera puede materializarse sin la existencia de al menos una mediana paz politica en el pais.

En general, el slstema milltar salvadoreño, a partir de la firma de los acuerdos de paz, ha enlrado en un proceso complejo (¿irreversible?), que tenderá a superar las laras del secular autoritarismo castrense, si es 
que el reino de la democracia ha comenzado. Aunque en un primer momenlo los militares se replegarán a los cuarteles, quedando inhabilitados para intervenir en el proceso político nacional (a todo nivel), es de esperarse que algunos segmentos busquen una inserción durable en el nuevo esquema político que la negociación lavorece; ya antes, algunos militares a lílulo individual (y en condición de reliro) y como producto de la dispersión orgánica que en la derecha salvadorena provocó el golpe de Eslado de 1979, ingresaron al partido ARENA, otros se adhirieron timidamente a PAISA dirigido por un militar ex-ministro de agricullura del gobierno derrocado en 1979, y no se descarta que el restituido pertil conservador que hoy ostenta el PCN (otrora "partido oficial", con injerencia decisiva de la Fuerza Armada, desde su creación en los anos 60), sea la instancia más idónea para la emergencia de la plataforma política de la inslitución militar ${ }^{5}$.

La negociación no pudo encausarse lampoco por la vía de las Iransformaciones socio-económicas, debido a que la correlación estralégica de fuerzas de los proyectos polílicos lundamentales involucrados, era bastante equilibrada ${ }^{6}$. Para los sectores populares, que el FMLN no haya podido modificar las directrices del "modelo económico" actualmente en marcha, acarrea un cosio político no despreciable, pueslo que lo que no se alcanzó en la "mesa" con suma dificultad pueda reivindicarse en el instrumento ad-hoc creado para debatir de manera permanente algunos de los problemas socio-económicos salvadorehos. Y es que el Foro de Concertación Económica y Social, no va a poder trocarse en el centro neurálgico que defina los ejes básicos de la conducción económica del pais. Varias razones para ello: a) las inslancias del capilal en su expresiones gremiales más significativas (Cámara de Comercio e Industria, Asociación Salvadoreńa de Industriales y Asociación Nacional de la Empresa Privada) si son representativas de los sectores empresariales nacionales; b) el movimiento laboral organizado, aunque constituido por no pocas organizaciones, su representatividad es limitada, ya que el vasto mundo de la informalidad urbana carece de expresiones gremiales aunque no así de presencia económica. $Y$ si quisiéramos ir más adelante en esto, puede asegurarse que los centros de trabajo vinculados a la producción manufacturera ("cordones industriales"), duranle los 80 vieron menguadas casi hasta la minima expresión las formas organizalivas tradicionales (los sindicatos) a Iravés de los cuales se expresó el movimiento obrero industrial; y hasla en lo que respecta a los asentamienlos populares urbanos (colonias ilegales, mesones, lugurios, campamentos, urbanizaciones "populares", elc.), el aclual movimiento comunal no es necesariamente su expresión. 
Sin embargo, las aseveraciones anteriores, no es que descalifiquen al actual movimiento popular ni mucho menos, sino que intentan mostrar sus reales limites, que sin duda se reflejarán en el presente proceso político post-bélico. AsI, la Unión Nacional de Trabajadores Salvadorenos (UNTS), por su composición social, está más en capacidad de esgrimir las reivindicaciones históricas de la población campesina salvadorena que las de la población urbana. $Y$ aqul vale la pena detenerse un poco, en un aspecto que no siempre es considerado en las luchas sociales actuales; y es que la realldad salvadorefia ya no puede segulr conslderándose tiplcamente agrarla, pueslo que en los últimos 30 anos se han producido sensibles modificaciones en el sistema urbano nacional ${ }^{7}$, que nos indican que las lendencias de poblamiento urbano ( $y$ en especial en el Area Metropolitana de San Salvador -AMSS-) constituyen un lenómeno socio-económico de significación determinante. Pudiera argumentarse que en el seno de la UNTS hay organizaciones que tienen como asiento de su actividad reivindicativa las ciudades, y es cierto, pero también se debería agregar que los sindicatos en el aparato estalal, en verdad no son por su vinculación a procesos productivos esenciales (salvo excepciones como los trabajadores de CEL, ANTEL, ANDA), los sectores laborales estratégicos del pais; a lo que se debe agregar el hecho real de que por su condición salarial, los trabajadores estatales constituyen una capa soclal popular no tan pobre. También, movilizarse en San Salvador, no es sinónimo de retomar las explosivas revindicaciones urbanas.

Algo similar pudiera decirse de la Cenlral de Trabajadores Salvadorehos (CTS), que aunque siguiendo una orientación político-ideológica un lanto distinta que la UNTS, lambién ha centrado sus mayores y mejores esfuerzos en las insliluciones del Eslado; en la Unión Nacional Obrero Campesina (UNOC), el sesgo rural es más importante que el trabajo sindical en las instancias estatales.

Por todo ello (que consideramos una debilidad organizativa), y porque la perspectiva modernizante de los grupos empresariales seguirá su marcha, el Foro de Concertación Económica y Social va a constiluir un espacio político cruzado por múltiples tensiones y equívocos que no to dejarán desarrollarse. Finalmente, habria que decir a este respecto, que desde el movimiento popular la concertación no puede visualizarse como el escenario donde el proceso revolucionario se materializa, es decir, la concertación (o su posibilidad) tiene lugar en el pais como resullado inmedialo del proceso negociador, y servirá más para "atajar" el desboque socio-político del periodo anterior que para imprimir un nuevo sello a la realidad socio-económica salvadorena. Ya lo declamos: la correlación 
de fuerzas del carmpo popular "no daba" para más. A pesar de lo anterior, no quiere decir que no sea un lugar polftico (inexislente en el pasado), que pueda ser favorable a los intereses populares.

Para las gremiales empresariales, se trata de una experiencia inédita, que no deja de provocar inquietud, en tanto que el verticalismo e "impunidad" de la gestión empresarial connaturalmente hisióricos al sistema económico salvadoreno, por primera vez liene un "dique", o sl se quiere, un "filtro". Pero también podria derivarse del Foro, que las luchas sindicales (sobre 1odo) se vean amarradas a la concertación; sin embargo, esto dependerá de la dinámica y estilo propios del movimiento popular.

\section{II}

Aunque la guerra, parece ser una siluación ya superada, no es ocioso examinar en líneas generales su fase linal negociada, ya que de esta introspección, creemos, pueden salir pistas inleresantes para el futuro polílico inmediato.

Al remitimos al terreno militar en sentido estricto, desde $1987-88$ se constataba un verdadero "empate", que se tradujo en un empantanamiento en el curso cotidiano de las acciones bélicas. No existla, ya en ese momenlo, ni de parte del FMLN ni de la FA, la posibilidad de que con sus esfuerzos de coníronlación bélica se llegara a la conformación de un nuevo cuadro de la situación nacional. El escalamiento de la guerra (=utilización amplia de diversos niveles de armas, esto es, desde explosivos caseros hasta misiles), era hasta antes de 1992, total, y se tralaba de una línea de desarrollo ya desplegada y que no lenía perspectivas de éxito político. En otras palabras: por la via de la guerra, se habian agolado las expeclativas de un cambio en la correlación de fuerzas. No obstante ser contundente esta realidad política, no era dominante dicha percepción en los actores principales de la lucha social salvadorena.

Entonces, ¿cómo se llegó a la mesa de negociación, en úlima instancia, si nadie perdió aquí la guerra? Pues resulta que el factor internacional, decisivo desde 1980 en el proceso político interno, después de los acontecimientos violentos de noviembre de 1989 (ofensiva del FMLNreacción FA), se activó de lal manera que ninguno de los actores de la guerra pudo rehuir sus delerminaciones (sin olvidar que el pivole fue la situación mundial de resolución negociada de conflictos). La negociación se impuso, como producto lógico del aclual cuadro internacional. Pero también debe considerarse, que en ningún momento de los anos 80 , en El Salvador se gestó ni desarrolló un sentimiento y movilización naciona- 
les -de amplia extension- en favor de un acuerdo global al contlicto. Si se pondera con objetividad, debe apreciarse que los empenos aglutinadores que se conformaron en el campo popular en esta dirección, tenian poco arraigo de masas, no eran espontáneos ni desecandenaron respueslas colectivas imporlantes ${ }^{\bullet}$. Esto cobra relevancia al constatar, que un aproximado del $50 \%$ de los salvadorenos-ciudadanos (si consideramos los últimos resultados electorales de 1990), se encuenlran al margen del proceso político; siendo un indicador bastante confiable, que corrobora esta hipótesis, el elevado abstencionismo electoral que durante los anos $\mathbf{8 0}$ se convirtió en la conducta política dominante y natural.

Vistas asi las cosas, ¿qué se negoció? La FA-gobiemo ARENA procuraron adelgazar al máximo, en la mesa, las exigencias del FMLN, conscientes de que no había derrota militar de por medio. No luvieron la iniciativa negociadora, de ahí que durante todo el proceso, las posiciones posilivas visibles antes del acuerdo linal, fueron las concesiones "pactadas" (algunas reformas a la Constitución, apertura a discutir el tema Fuerza Armada, documento-compromiso sobre Derechos Humanos). Por ratos pareció que se negociaba la crisis nacional, pero en realidad lo que se buscaba (desde el campo dominante) era concrelar el cese de las hostilidades, que no es 10 mismo. Desde la perspectiva gubernamental pues, no se estaba negociando ni el sistema político ni el ordenamienlo socio-económico. Pero era lan contundenle la relevancia político-militar del adversario, que no se pudo evadir la agenda negociadora.

Un atisbo de solución verdadera para El Salvador, conslituirla la disolución completa de todos los aparalos coercitivos (incluido el ejército, por supuesto) de la sociedad política y el arribo a un marco socio-económico que bloquée la marginación y exclusión de los sectores populares de los beneficios del progreso malerial. Por el carácter progresivo de esta perspectiva, no puede esperarse que brote de un "desarrollo nalural" de la sociedad salvadorena, tendría que ser catapulteada por un proyecto polrtico de contenido translormador. Desde un punto de visla global, el FMLN es un decidido animador de ese proyecto, pero producto de to complejo que se ha lornado el proceso de lucha social y lambién por el impacto sensible de los propios yerros que como luerza política ha cometido, no se encuentra en el momenlo actual con la correlación de fuerzas suficiente para sostener los objelivos básicos que lo convocaron a la guera. Con el agravante, ahora, de que cualquier modíficación de la situación nacional, pasa sólo por el nivel de convocatoria que se lenga. $Y$ aquí, no tienen que ver únicamente los resultados electorales, sino que deben considerarse lodos los mecanismos activadores de la sociedad civil. 
Debido a estas consideraciones, creemos que el proceso negociador fue sui generis, y aunque al enderezarse la situación del pals a cierto punto de equilibrio ("paz armada" hasta octubre 92), es probable que se logren "desmontar" los aparatos de la guerra, pero no hay sólidas garanlias de que se desactive la conflictividad social explosiva, que hunde su logica en los agudos apremios que padecen la mayoria de salvadorenos en los afanes de la sobrevivencia.

Por las caracteristicas intrínsecas del proceso salvadoreho, los acuerdos finales de Nueva York, eran lo único que se podla alcanzar en El Salvador, dado el equilibrio estratégico de fuerzas. No se trató (desde la perspectiva popular) de una negociación "victoriosa" como la que luvo lugar en Vietnam en la década de los 70 , ni de un desarme sin compromisos fundamenlales que afectaran el sistema político, como fue el caso de la "conira" nicaragüense en 1990. Tampoco es muy acertado tratar de encontrar identidades mecánicas con lo que aconteció en Colombia a partir de la incorporación al esquema político constituido, del contingente socio-político del Movimiento 19 de abril (M-19) a finales de la década pasada. Más bien, nosotros sugeriríamos que para la experiencia salvadorena, lo que se ha presenlado es una negociación con coslos compartidos.

Sin forzar las distancias históricas (y tratando de prefigurar escenarios), creemos que la situación salvadorena se acerca bastante - al menos en estos primeros meses- al cuadro planteado (que no se desarroIlo, debido al golpe de mano dado al proceso de paz, por lo que después se llamaria el grupo Somoza) como consecuencia de las luchas desencadenadas por el Ejército Defensor de la Soberanía Nicaragüense (EDSN) encabezado por Sandino, entre los anos 1927-34.

Aunque esla similitud lentaria a proponer conclusiones apresuradas, es oportuno decir que lo que ocurre en El Salvador, se asemeja a las condiciones que se presentaron en los tiempos del EDSN de Sandino, por su significación política ${ }^{\circ}$ y no necesariamente por su dimensión específica. En ese sentido, intentar hacer un acercamiento preliminar a las particularidades correspondienles a la situación salvadorefía resulta provechoso, que sin ser exhaustivo, pudiera servirnos talvez para estructurar una idea más coherente del proceso político nacional inmediato:

A) No estuvo presenle la derrola militar del FMLN, pero lampoco el régimen dominante, en ese mismo terreno, logró ser quebranlado. Una evaluación ponderada de la ofensiva de noviembre 89 , daría como resullado una ralificación de esle "empate militar".

B) La guerra alcanzó el mayor escalamiento probable (hasta el uso de 
misiles) en momentos en que la participación política de los sectores populares era modesta.

C) El desarme de las fuerzas militares del FMLN, se hace a cambio de la eliminación de todo el aparataje de seguridad y coerción que por décadas se encargó de manlener el "orden" en el país y también como conlrapartida a una reducción sustancial del ejército oficial; si para octubre 92 no se presentan las condiciones pacladas por las partes, el acuerdo se truncaría y la siluación política evolucionaria en una dirección desconocida que provocaría un nuevo reacomodo de fuerzas. Quizás no una guerra como la vivida en los 80 , pero si un escenario de desobediencia civil caólico'0.

D) No están planteadas, como producto de la negociación, transformaciones estruclurales en lo económico-social (en un sentido nacional), es decir que modifique el lamentable estado de reproducción malerial y espiritual de los salvadorenos, y aquí entró en juego la variable correlación de fuerzas, como lo sefialáramos lineas arriba; a eslo se agrega el hecho de que el desgaste producido por la aplicación de las relormas sociales en manos de la Democracia Cristiana, durante la década de los 80, anuló la probabilidad de alcanzar ese "lecho mínimo" para los sectores populares. El traslocamiento de las eslructuras agrarias (=reforma agraria en cualquiera de sus versiones), quedó fuera de acuerdos, y sigue siendo una mela a alcanzar por medio de las nuevas conquistas que pueda materializar la organización popular. También queda fuera de consideración, el proceso de reactivación económica emprendido desde 1989.

E) En los territorios controlados (y algunos de sus alrededores más próximos), quedaria modificado de hecho el ordenamiento económico, social y político previo a la guerra. Las tierras reivindicadas dentro de esos linderos se intentarían legalizar, para salvar el escollo de la legalidad conslitucional referente a la propiedad, pero en la práctica quedaria en evidencia el poder paralelo que representa el FMLN.

F) El FMLN se ve apremiado (que no obligado) a limitar su aclivar organizativo al ámbito de lo político-electoral. Y es que un partido político es mucho menos que una luerza politica.

G) La fisonomia de la Fuerza Armada se ve restringida, como ya lo apuntáramos anles, en su dimensión política, pero queda sin determinar lo concernienle a la autonomía económica alcanzada por el sector militar (acumulación visible y conmensurable durante la década de los 80 : IPSFA, etc.). Su reacomodo en este sentido, de manera implícita estaría garantizado por lo acuerdos. 
H) El movimienlo popular es hoy más que nunca, una madeja compleja de contradicciones:

-cuenta con un soporte financiero más o menos eslable, pero a nivel organizativo la masividad no es su caracteristica distintiva (como a finales de los afios 70);

en ese senlido, aunque el movimiento popular abarque e incida en más segmentos sociales que antes de 1980, su radio de acción en cada caso es de suyo restringido;

- su influencia política está ubicada por sectores, mientras que la terrtorlalldad no es el eje de su configuración, siendo a partir de ésta donde las luchas sociales podrían tomar olro rumbo;

- ll movimiento sindical, como ya lo sugerlamos antes, liene mucho mayor beligerancia que en los primeros 6 antos de la década pasada y con capacidad de impactar a la "opinión pública", pero está conformado su dinamo básico por el sector de empleados públicos, siendo la presencia de los trabajadores productivos (formales e informales) de poca monta;

-por su tradición confrontativa y contestataria, el movimiento popular enfrenta la hora aclual sin una propuesta local y nacional que dé respuestas específicas ( $y$ viables) a las necesidades de los sectores populares, yendo más allá del paternalismo y el asistencialismo. La concepción autogestionaria, aún es una declaración de buenos propósitos, y no un proyecto en marcha;

-las inslancias cooperalivas (CONFRAS, COACES, etc.), son una buena base para el despegue de una perspectiva económica de nuevo tipo, pero ni su práctica productiva de 10 anos reciemles tiene saldos positivos, ni su sustrato polílico es lo tan sólido a nivel de base (aunque la radicalización de las cúpulas dirigenciales, sea más que explicita), como para promover una inserción novedosa en la economla nacional";

-en las repoblaciones (Segundo Montes, Nuevo Gualcho, Santa Marta, Guarjila y oriente de Chalatenango), se presentan talvez los escenarios más nítidos de una búsqueda de formas de convivencia social (distintas a las hoy dominantes en el país), pero sin poder sortear favorablemente aún los draconianos límites de la mera sobrevivencia;

-n las ciudades (y con especial énlasis en el Area Metropolitana de San Salvador), como ya también intentáramos adelantar al inicio, el movimiento comunal, cuya cobertura es a penas perceptible, no obstante contar con una importante base tinanciera, de seguir manteniendo su actual fisonomía con mucha dilicultad podrá expandirse y mucho menos 
masificarse. En un sentido estricto, no hay movimientos urbanos de significación, to que si existe es una presencia política de organizaciones populares en las ciudades, pero reivindicando aspectos de relevancia nacional. No hay eclosión de luchas sociales en los territorios urbanos per se.

-l llamado movimiento de mujeres, cuyo desarrollo puede rastrearse con la conformación de los frentes de guerra en 1981 (Asociación de Mujeres Salvadorefias, AMES), al ensayar su accionar por ejemplo en el Area Metropolitana de San Salvador, no logra salir del marco estrecho de pequenos circulos de mujeres, que en el mejor de los casos su militancia política está en otras instancias del movimiento popular; y en otras ocasiones el empeno organizativo se ha reducido a la apertura de oficinas de "atención" a los problemas de la mujer. $Y$ esto, en ningún sentido, minusvalora la participación polítilca de las mujeres salvadorenas, sino que propone una visión critica de las formas, metodologias y prácticas concretas que desde la izquierda nacional se han asumido en la lucha social los problemas específicos de las mujeres. No es un problema de composición social, pero poco se puede avanzar a nivel organizativo, si no se consideran realldades tanglbles de la socledad actual, como serían la significación económica y social del trabajo doméstico en el pals, el no reducido número de mujeres "trabajadoras de la calle" (vendedoras ambulantes de todo tipo de mercanclas, puestos de comida, etc.), la presencia nolable de mujeres en las fábricas textiles (en la planta o en los niveles de subcontralación como en los procesos de maquila). $Y$ aqul habria que agregar lenómenos como el de la violación sexual, que no debería lratar de intervenirse a posteriori, sino en el escenario donde se incuban eslos procesos ${ }^{12}$.

\section{III}

Los logros macroeconómicos de la gestión gubernamental del ano 1990, dieron lugar a cierta confusión, en tanto que no se percibió que sólo eslaban réllejando un momento de todo el proceso económico. No se consideraban en esos resultados, los desequilibrios estructurales que socavan la estabilidad social del país. El problema esencial y único para El Salvador, no es si se reducen los Indices de inflación, o si el déticit fiscal se logra contraer con la reducción de los gastos del aparato estatal. Desde luego que la gobernabilidad macroeconómica es condición sine qua non para emprender un proceso de reactivación económica. Sin embargo, aunque los programas de ajuste estructural se tornan un imperalivo para las economlas de mercado latinoamericanas, el dilema no 
resuelto es el allo cosio que los sectores populares deben pagar, como regla general, resultado de estas políticas económicas restriclivas. Por esio es que, de no buscarse cauces efectivos para contrarreslar la depredación socio-económica de los salvadorefios más pobres, lo que se estará postergando es el estallido de nuevo proceso de insubordinación social, "herederos" de los vividos después de 1980.

No se trata de apelar en estas reflexiones, a las ya conocidas políticas redistributivas, que de alguna manera ( $y$ en los más distinlos matices) se han aplicado en diferentes momentos de la hisloria contemporánea de América Latina, con renovada insistencia desde 1960, y que han conlado con el aparataje estatal como platalorma impulsora de esos empenos. Ya este "ensayo" se hizo en los anos 80 en EI Salvador, con los resullados (del dominio público) de caida de la producción nacional en general, pérdida de productividad en los rubros más dinámicos, endeudamiento externo crecienle, déficil fiscal casi inmanejable, desequilibrio permanente en la balanza de pagos, elc. Aunque no ha sido necesariamente por el sólo hecho de que el Estado se conslituyó en el eje de las modificaciones redistribulivas (reformas sociales), el factor que llevó al fracaso de dichas políticas económicas; sino que, fue el contenido especifico del proyecto polilico dominanie en los 80 , 10 que más inviabilizó y deformó algunos aspeclos positivos de las relormas, dado su permanente inclinación hacia la conlensión social y neutralización política conteslaria.

Lamenlablemente, para El Salvador, debido a la ausencia de originalidad en los planteamientos proposilivos de las luerzas politicas más importantes, sólo se encuentran en discusión o visiones antiestatistas - que es lo que se está desarrollando en la actualidad—, que dejan a las leyes del (¿omnimodo?) mercado la última palabra en la reproducción material de la sociedad; o se esgrimen atisbos de visiones pro-estatistas, que seria lo que se desprende del conjunto de los planteamientos públicos hechos por el conjunto de la izquierda salvadorena, que aunque enarbola los eslandarles de la juslicia social, al no abrirle paso en la práctlca concreta (y lalvez tampoco en lo teórico) al protagonismo económico autónomo y a la participación politica multidireccional de los distintos segmentos de la socledad clvil, ve en tendencia menguados sus posibles efeclos redistribulivos y de democratización ${ }^{13}$.

Al ponderar la situación nacional desde la dimensión de los agentes económicos, nos encontramos con un panorama en mutación, si lo comparamos con el cuadro económico de los af́os 70 . En el momento presente, en ese sentido, se pueden observar con claridad varios agrupamientos de sectores económicos, que en su dinámica reproductiva 
cotidiana confluyen, se repelen, conviven o se ignoran. Estamos hablando entonces de:

A) El tradiclonal capital privado, hegemónico en las zonas de agroexportación, en la importación a gran escala, en los cordones industriales localizados en el AMSS fundamentalmente y en los servicios de cobertura nacional. Sus planteamientos pueden cotejarse en las cotidianas proposiciones que difunden a través de los medios de comunicación las diferentes asociaciones y gremiales (ASI, Cámara de Comercio e Indusiria, Asociación Cafetalera, ABECAFE, etc,).

B) El Estado, y lodo lo que comprende su inserción en la esfera económica (CEL, ANDA, ANTEL, municipalidades, BFA, ISSS, etc.) en forma direcla o indirecta; aunque en la coyunlura actual por la filosofía económica en que se inspira la dominante gestión gubernamental, el margen de ingerencia del aparato estatal eslá siendo cueslionado, de cualquier manera siempre será importante.

C) El segmenlo de la pequef́a y medlana propledad (rural y urbana), que durante eslos afios de la crisis nacional, ha visto bastante delimitado su ámbito de reproduccción material, tanto por sus carencias como por sus potencialidades, logrando expresar sus intereses (de los seclores más politizados -y minoritarios, por cierto-) a Iravés de algunas gremiales (SCIS, AMPES, FENAPES).

D) El heterogéneo seclor cooperatlvo (en su expresión de movimiento socialy también en su pura expresión económica), que es casi un resultado no-deliberado de las recomposiciones habidas en los anos $\mathbf{8 0}$. $Y$ es aqui precisamente, desde una perspectiva de cambio social (como los proponiamos ya), donde se podrian gestar iniciativas interesantes para las opciones del desarrollo nacional, toda vez que no se plense que por si solo este sector económico es la soluclón.

E) El Intrincado (cconluso?) mundo de la Informalidad laboral urbana y la precarla producclón minifundisla. La primera, abarcando a un porcenlaje nada despreciable de la población económicamente acti$\mathrm{va}^{14}$ y cuya expansión exponencial ha lenido lugar en la década de los 80; la segunda, es el conocido secior de campesinos pobres, que durante una parte del ańo se dedican a la producción para el autoconsumo y el resto lo dedican a la venta de su fuerza de trabajo (en su mayoria) en las zonas de agroexporlación.

F) La poblaclón asalarlada-formal (tamblén en su expresión de movimlento soclal), que es asimismo sumamente heterogénea puesto que va desde los empleados públicos hasta los obreros industriales. 
Aunque, en América Latina, hay ya infinidad de enfoques al respecto de la democracia, sobre todo a partir de 1980, nosotros en esta parte tenemos interés por desarrollar algunas ideas-fuerza que no corresponden de manea obligada a una zona exclusiva de la agenda democrática, pero que suponemos nos permitirán comprender los escenarios futuros para el proceso político salvadorefio:

A) Si las prácticas políticas esenciales quedan amarradas por la camisa de fuerza que signilica la celebración de los tradicionales procesos electorales, la dinámica del desarrollo de la democracia en El Salvador, será penosa. Aunque es cierto, de que si comparamos con los eventos electorales de los afios 60 y 70 , el factor-fraude no va a tener cabida, lo cual es en verdad una ganancia para el sistema político nacional. Pero eso no es suficiente para configurar un marco electoral de amplia oxigenación. La garantía de que los resultados serán respelados, no es más que un elemental canon de larga data en las democracias occidentales, y que sólo hasta ahora, en nuestro pais se cumple.

B) Por otra parte, la cultura politica no es un atributo que se derrame de forma automatica como consecuencia de los acuerdos de paz. El persistente autoritarismo (militar y no-militar), las modalidades verticalistas y dirigistas de muchas de las inslancias organizalivas de la sociedad polftica y la sociedad civil, la secular práctica de la representatividad que deja sin control la gestión política, la opción del abstencionismo frente a la iniquidad del pasado reciente, etc., son valladares que deberán superarse si es que el desafío democrático es un compromismo nacional. En un pais donde en por los menos los últimos 20 años el terrorismo de Estado y la guerra sucia se cebaron en los sectores populares, para paralizar los ánimos politicos, y donde en respuesta a loda esta injusta avalancha depredadora, los adherentes al proyecto revolucionario desencadenaron procesos de violencia popular, que no por justa dejo de impactar negativamenle a otros sectores sociales; constituyéndose en conjunto una matriz psico-social que no puede ser "desamada" por decreto, pueslo que se ha acumulado en la conciencia social de los salvadorefios. Pues bien, la cultura polílica democrática a la que apostamos, no puede evadir esta circunslancia. Lo que se inaugura con los acuerdos de paz, es un régimen de tolerancia política-ideológica, que si se logra institucionalizar, será un verdadero seguro de vida para la democracia salvadorefía. Que distinlos grupos políticos y económicos se empecinen en garantizar el desarrollo del capitalismo en El Salvador, ya no debería constituir un asombro, es una decisón razona- 
da, que aunque en lo particular nosotros consideramos a-histórica, bajo el marco de la tolerancia debe ser respetada de manera irrestricta la defensa y difusión de dicha programática, a condición de que no se conculquen a nombre de dichos preceplos las libertades democráticas, como fue la práctica reciente en nuestro país. De la misma manera, propugnar por un nuevo orden (llámese socialismo o como que se quiera) donde la injusticia social sea desterrada y el bienestar social no esté caracterizado por abismos económicos entre los distimtos sectores de la población, tampoco debería ser anatemizada esta opción.

C) Un rápido acercamiento a la trayectoria de los partidos políticos de El Salvador en la última década, muesıra sin forzar la realidad no pocos vacíos, y esto a pesar de que aunque desde inicios de la generalización de la guerra (1981 en adelante), fueron promocionados como los vehiculos por excelencia para que la vida política de los salvadorefos se expresara. Hoy, al eclipsarse el conflicto bélico, los partidos politicos son relanzados, como instilucionalidad, ungidos de los mismos atributos. Sin embargo, y talvez contrariando algunas ideas-cliché que se han ido imponiendo en el pais, no es cierto que estos (los que hasta hoy hemos conocido y padecido) partidos políticos estén en la capacidad de absorber el torrente fundamental del accionar político de la sociedad salvado. refia. Las prácticas clientelistas que han sido divisa clave en el desenvolvimiento de los partidos políticos, es una rémora que obsinuye la emergencia de una remozada cultura política. En los 80, los partidos de la derecha (en sus más curiosas variantes) apremiaron a la población para que entregara su volo, casi como la tabla salvadora que solucionaría el entorno caótico que se vivia. Acudir a las urnas, casi como borregos, no deberla ser sinónimo de expresión de voluntad política ciudadana.

Si la democracia se busca como objelivo esencial para el conjunto de la sociedad, la democracia intema debería primar en el seno de estas formaciones organizalivas; pero nada hay más alejado de esto: en un partido lan magullado como el PCN los "movimientos de cúpula" eslán por encima de toda consideración, ya que las bases (que en efecto tienen, no importa para efeclos de esla reflexión, cuáles son los lazos que les dan identidad) no son parte de los niveles de decisión. Esta forma de hacer política, no sólo no conduce a la ampliación de los espacios de participación ciudadana, sino que contribuye a la atrofia del imaginario politico.

D) Pero el cuestionamiento al sistema electoral, en el que se inscriben los actuales partidos políticos, debe llevarse más adelante. Aunque en los acuerdos de paz, se asumen tal cual (por parte del FMLN) los mecanismos electorales vigentes, esto no nos debe llevar a aceplar 
como lo mejor para nuestro país, eslas formas clásicas de canalizar los impetus ciudadanos. Se eligen autoridades generales (presidencia y asamblea legislativa), así como las autoridades municipales, pero por el cargado sesgo representativo, los dislinos sectores sociales al entregar su voluntad polftica a través del acto de emitir el voto, se "abandonan" a lo que los elegidos (y sus intereses corporativos) decidan. Y no hay manera de acompanar el ejercicio de la gestión polltica, porque se deben esperar las siguientes elecciones para poder incidir. Nos parece que esle clclo Inútll, se ha reforzado debido a que no se han querido ampliar (en concepción y en los hechos) los espacios para que los dislintos sujetos polfticos (que no sólo son los tradicionales partidos) formen parte del abigarrado espectro que canaliza la volunlad ciudadana. Pero aún más: de acuerdo a las características espaciales, económicas. poblacionales y políticas, de por ejemplo el Area Metropolitana de San Salvador, en lugar de pensarse desde el clientelismo sólo en términos de miles de votos para ser cooplados, una concepción de territorlos polittcos donde las prácticas electorales no sólo respondan al calendario nacional sino que estén presentes de manera permanente, sería una verdadera novedad. Esta visión es correlaliva a un elemental cotejo con la realidad social urbana, donde es a partir del territorlo que se "conslruye" la reproducción malerial y espiritual de los salvadorenos. Desde la perspectiva de los seciores populares, esta dimensión de lo electoral podria permitir romper en el corto plazo con las aberraciones clientelistas hoy dominanles. Pero esto implicaría altas dosis de democratización en todos los espacios donde la población incursione.

E) Además, habría que decir que hacer politica en El Salvador debe sufrir una dráslica redefinición, y no constrefirlo sólo a la oportunidad que se presenta de acceder a los cargos públicos. Aqui es donde surge con toda propiedad la presencla politica real de las distintas organizaciones populares. Cuando en los af́os 70 el autoritarismo canceló los espacios públicos y la oportunidad de la disensión, el surgimiento de nuevas modalidades politicas se convirtió en un imperalivo. A las organizaciones populares de la década de los 70 , nadie les "aulorizó" su vigencia, eran (para usar un lugar común: ilegales), se legitimaron en la medida que fueron ligando su hacer político a las más urgentes necesidades de los seclores pobres del pais. La fragua de las luchas sociales, fue el tamiz que hizo crislalizar el vasto movimienlo de masas que se consolidaría a principios de los afios 80 y que conslituyó la plalaforma social que sirvió de soporte para la generalización de la guerra. Es más, podria asegurarse que el resquebrajamiento del régimen político lutelado por el PCN y la Fuerza Armada y que se materializó con el golpe de Estado de 1979, no hubiera sido posible sin la existencia del movimiento 
popular. Constituirse en interloculor válido en el proceso político nacional, no es una concesión, sino una conquista. De igual manera, el actual movimiento organizado de las masas que se fue estruclurando después de 1981 (que aunque en su composición, amplitud, dinámica, es bastante distinto del de la década de los 70), también adquirí́ legitimidad (amén de ciertos niveles de legalidad) como producto de los procesos revindicativos desencadenados. En ese sentido, si bien es cierto que no eliminamos la existencia de los partidos politicos, creemos que la consIrucción de una sociedad democrática debe permilir la pluralidad de agentes para viabilizarla. Tampoco estamos idealizando a la actual organización popular, reivindicamos su vigencia como forma política, pero también habría que decir, que de no experimentar un intenso proceso democratizador en su interior, el camino hacia la configuración de un proyecto popular autónomo en lo económico y plural en lo politico, se verá más lleno de abrojos.

\section{NOTAS}

1. Aunque de manera formal, la negociación linalizó con el desarme de un contingente significativo de la "contra", al producirse la derrota electoral del sandinismo y abrirse (por derivación) espacios públicos para cuestionar las conquistas de la revolución nicaragüense, se contormó a gran velocidad un nuevo escenario político donde la desobediencia civil adquiríb relevancia inusitada, siendo aprovechada tanlo para delender el orden constitucional originado por la revolución, como para desvirtuarlo.

2. Puede rastrearse la trayectoria de las expectativas de cambio social desde 1979 hasla 1992, en los distintos números de la revisla Estudios Centroamericanos (ECA) de la Univerisdad Centroamericana "José Simeón Cañas".

3. Existe ya una variada bibliogralia al respecto de la Fuerza Armada, sobre todo en lo concerniente a su papel de lactor punitivo. A manera de ejemplo, pueden consultarse los siguientes materiales: OBSTACULOS A LA REFORMA: UN ANALISIS DE LOS DIRIGENTES MILITARES DE EL SALVADOR (Comisión de Control de Armamentos y Política Exterior del Congreso de los Eslados Unidos), Washington, 1990; "La Fuerza Armada salvadoreña: una tuerza para sl misma", New York Times Magazine. New York, 1989; EL HORROR SALVADOREÑO O LA GUERRA SUCIA EN NOMBRE DE LA LIBERTAD, San Salvador, 1983.

4. Ya en 1989, una rellexión preliminar adelantaba algunos aspectos acerca de la significación polílico-económica de la emergencia del "grupo-Cristiani". Se decía: "Una de las grandes diferencias existente entre la gestión gubernamental demócrata-cristiana y la hoy republicana nacionalisla, estriba en que para recomponer el modelo socio-económico en crisis (reactivándolo prime- 
ro, para luego trazar las "nuevas" pautas de crecimiento económico) se cuenta con un bloque económico-social que respalda esta perspectiva de acción. De aqul se desprende, que el programa de trabajo del nuevo gobierno sea más fluido y coherente (aunque no exento de discontinuidades). Pero algo más: no sólo hay una base social propietaria que ampara este esfuerzo, hay también una conducción concreta (que se Iraduce en hegemonla polltica) de algunos capitales que quieren marcar el ritmo del quehacer politicoeconómico de la administración". "La nueva gestión. Lineas de reflexión", EI Salvador (En Construcción), REGION-Estudios y Asosoría, 5, San Salvador, 1989.

5. Por el momento político que se vivla a principios de los 80 , los elementos militares que ingresaron a las filas de ARENA (como fundadores o después de estructurado el partido) no parece que lo hicieran como grupo. En cambio, el respakdo que el PCN puede recibir de la FA en los 90, de manera necesaria será como cuerpo social. La presencia del general Oneclfero Blandón (ex-jefe del estado mayor) en la sub-comisión de COPAZ para la Policia Nacional Civil como delegado del PCN, sugerirla la búsqueda de espacios de participación polltica para los militares.

6. En entrevista reciente Schatik Handal dice al respecto: "El tema más diflcil, más largamente negociado, fue el de las fuerzas armadas. Se trata de un tema muy sensible, pueslo que al principio nosotros mantenlamos la demanda de una disolución completa. O sea, desaparición del ejército y, de manera simultánea, desaparición de las fuerzas del FMLN. Pero esto no pudo alcanzarse. Aunque nuestra propuesta tuvo gran apoyo, la correlación de fuerzas dentro del pals no nos permitió, en definitiva, llegar hasta ese punto". "Habla Schafik Handal", El Salvador en_construcción.REGION-Estudios y Asesoría, 9, San Salvador, 1992.

7. En 1960 la población urbana con respecto a la población total salvdoreña constituía el $38.5 \%$, en 1970 era el $50.6 \%$ y en 1980 ascendi6 al $55.8 \%$. Clr. LO URBANO. TEORIA Y METODOS, EDUCA, San Joś, 1989.

8. SI hubo una persistente actividad de apoyo a la negociación, pero de parte de las organizaciones sociales vinculadas a la izquierda, aunque la masividad no era su caraclerística principal.

9. Del Acuerdo de Paz, firmado entre las fuerzas sandinistas y el gobierno de Nicaragua el 2 de lebrero de 1933, extractamos algunos aspectos que nos sirven para buscar la similutud referida: "Los delegados del general Sandino y de los partidos, reconocen la conveniencia de cimenlar prácticamente la paz en el territorio de la República, mediante la dedicación fructífera al trabajo de los hombres que militan al mando del general Augusto César Sandino y. asimismo, mediante el abandono gradual de sus armas (...) El Ejecutivo presentará al Congreso Nacional la iniciativa de amnistla amplia por delitos políticos y comunes conexos, cometidos en el perlodo que se comprende del 4 de mayo de 1927 hasta la fecha de hoy (...) incluyéndose en los beneficios de la amnistía a cien personas del mencionado ejército, que podrán conservar sus armas temporalmente para el resguardo de la zona del terreno baldio en que lendrán derecho a fincarse y laborar todos los que hubieran pertenecido a dicho ejército (...) La zona de terreno baldío destinada para las 
labores y a que se refiere el inciso (a) de esle acuerdo, habrá de localizarse con suficiente amplitud en la cuenca del Rlo Coco o Segovia, o en la región en que convinieran el Gobierno y el general Sandino (...) El Gobierno mantendrá en toda la República y especialmenle en los deparlamentos del Norte, por el término minimo de un año, trabajo de obras públicas en los cuales dará colocación prelerente a los individuos del ejército del general Sandino (...) Para facilitar el desarme de parte de las fuerzas del general Sandino y dar abrigo provisional a éslos, se designa la población de San Rałael del Norte, encargándose al mismo general Sandino el mantenimienlo del orden durante el tiempo que el Gobierno juzgue conveniente". PENSAMIENTO VIVO DE SANDINO (Tomo 2), Editorial Nueva Nicaragua, Managua, 1981.

10. El caso nicaragüense (ya lo declamos) después de la derrola electoral sandinista, es un ejemplo aleccionador del tipo de ingobernabilidad sociopolítica a la que hacemos relerencia.

11. Pueden observarse ciertas características de la dimensión económica de este sector en: LA SITUACION ACTUAL DEL COOPERATIVISMO EN EL SALVADOR, CSUCA/UES/COACES, San Salvador, 1991.

12. El detalle del accionar (en 1990) de una de las organizaciones de mujeres, CONAMUS, refleja con bastante nitidez que las lineas de trabajo de estas inslancias no se abocan necesariamente a retomar las urgentes reivindicaciones de las mujeres trabajadoras salvadoreñas, lo que ha redundado en un crecimiento reducido de su capacidad orgánica. Ctr. Palabra de mujer. Coordinadora Nacional de la Mujer Salvadoreña (CONAMUS), 1, San Salvador, 1990.

13. De acuerdo a la Proclama a la Nación, se propugna por que "El Estado debe ser fuerte económicamente para asegurar los recursos que le permitan cumplir con estas obligaciones (salud, anaffabetismo, etc.)... Para fortaleza $\bullet 00$ nómica del Estado se nacionalizará la banca y el comercio exlerior". Estudios Centroamericanos (ECA), Universidad Centroamericana "José Simeón Cañas", 503, San Salvador, 1990.

14. Según dalos recientes del Minislerio de Planificación y Coordinación del Desarrollo Económico y Social (MIPLAN), la población económicamente activa comprendida en el llamado sector informal, es de alrededor de 485,041 personas (sin incluir el trabajo doméstico), y las personas que trabajan en el sector moderno es de 441,437. EVOLUCION ECONOMICA Y SOCIAL, MIPLAN, San Salvador, 1990. 